\title{
Testing pterosaur ingroup relationships through broader sampling of avemetatarsalian taxa and characters and a range of phylogenetic analysis techniques
}

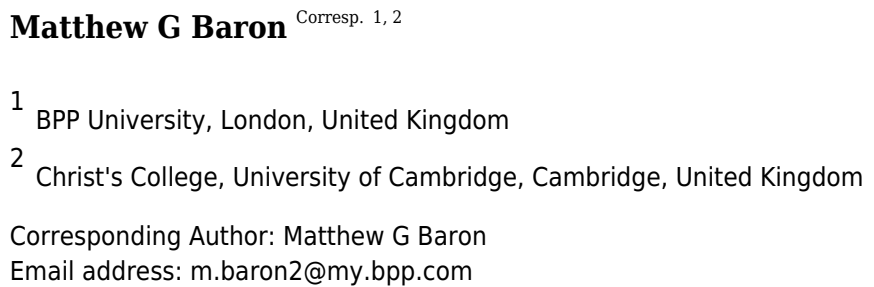

The pterosaurs first appear in the fossil record in the middle of the Late Triassic. Their earliest representatives are known from Northern Hemisphere localities but, by the end of the Jurassic Period, this clade of flying reptiles achieved a global distribution, as well as high levels of diversity and disparity. Our understanding of early pterosaur evolution and the fundamental interrelationships within Pterosauria has improved dramatically in recent decades. However, there is still debate about how the various pterosaur subgroups relate to one another and about which taxa comprise these. Many recent phylogenetic analyses, while sampling well from among the known Triassic and Early Jurassic pterosaurs, have not included many non-pterosaurian ornithodirans or other avemetatarsalians. Given the close relationship between these groups of archosaurs, the omission of other ornithodirans and avemetatarsalians has the potential to adversely affect the results of phylogenetic analyses, in terms of character optimisation and ingroup relationships recovered. This study has addressed this issue and tests the relationships between the early diverging pterosaur taxa following the addition of avemetatarsalian taxa and anatomical characters to an existing early pterosaur dataset. This study has, for the first time, included taxa that represent the aphanosaurs, lagerpetids, silesaurids and dinosaurs, in addition to early pterosaurs. Anatomical characters used in other recent studies of archosaurs and early dinosaurs have also been incorporated. By expanding the outgroup taxa and anatomical character coverage in this pterosaur dataset, better resolution between the taxa within certain early pterosaur subclades has been achieved and stronger support for some existing clades has been found; other purported clades of early pterosaurs have not been found in this analysis - for example there is no support for a monophyletic Eopterosauria or Eudimorphodontidae. Further support has been found for a sister-taxon relationship between Peteinosaurus zambelli and Macronychoptera, a clade here named Zambellisauria (clade nov.), as well as for a monophyletic and early diverging Preondactylia. Some 
analyses also support the existence of a clade that falls as sister-taxon to the zambellisaurs, here named Caviramidae (clade nov.). Furthermore, some support has been found for a monophyletic Austriadraconidae at the base of Pterosauria. Somewhat surprisingly, Lagerpetidae is recovered outside of Ornithodira sensu stricto, meaning that, based upon current definitions at least, pterosaurs fall within Dinosauromorpha in this analysis. However, fundamental ornithodiran interrelationships weren't the focus of this study and this particular result should be treated with caution for now. However, these results do further highlight the need for broader taxon and character sampling in phylogenetic analyses, and the effects of outgroup choice on determining ingroup relationships. 
1 Testing pterosaur ingroup relationships through broader sampling of avemetatarsalian taxa

2 and characters and a range of phylogenetic analysis techniques

4 Matthew G. Baron ${ }^{1}$

5

6 1. BPP University, London, Aldine Place, 142-144 Uxbridge Road, London W12 8AW, UK

7 2. Christ's College, Cambridge, St Andrew's Street, CB2 3BU

8

9 Corresponding author: m.baron2@my.bpp.com

10

11

12

13

14

15

16

17 


\section{ABSTRACT}

The pterosaurs first appear in the fossil record in the middle of the Late Triassic. Their earliest representatives are known from Northern Hemisphere localities but, by the end of the Jurassic Period, this clade of flying reptiles achieved a global distribution, as well as high levels of diversity and disparity. Our understanding of early pterosaur evolution and the fundamental interrelationships within Pterosauria has improved dramatically in recent decades. However, there is still debate about how the various pterosaur subgroups relate to one another and about which taxa comprise these. Many recent phylogenetic analyses, while sampling well from among the known Triassic and Early Jurassic pterosaurs, have not included many nonpterosaurian ornithodirans or other avemetatarsalians. Given the close relationship between these groups of archosaurs, the omission of other ornithodirans and avemetatarsalians has the potential to adversely affect the results of phylogenetic analyses, in terms of character optimisation and ingroup relationships recovered. This study has addressed this issue and tests the relationships between the early diverging pterosaur taxa following the addition of avemetatarsalian taxa and anatomical characters to an existing early pterosaur dataset. This study has, for the first time, included taxa that represent the aphanosaurs, lagerpetids, silesaurids and dinosaurs, in addition to early pterosaurs. Anatomical characters used in other recent studies of archosaurs and early dinosaurs have also been incorporated. By expanding the outgroup taxa and anatomical character coverage in this pterosaur dataset, better resolution 
40 between the taxa within certain early pterosaur subclades has been achieved and stronger

41 support for some existing clades has been found; other purported clades of early pterosaurs

42 have not been found in this analysis - for example there is no support for a monophyletic

43 Eopterosauria or Eudimorphodontidae. Further support has been found for a sister-taxon

44 relationship between Peteinosaurus zambelli and Macronychoptera, a clade here named

45 Zambellisauria (clade nov.), as well as for a monophyletic and early diverging Preondactylia.

46 Some analyses also support the existence of a clade that falls as sister-taxon to the

47 zambellisaurs, here named Caviramidae (clade nov.). Furthermore, some support has been

48 found for a monophyletic Austriadraconidae at the base of Pterosauria. Somewhat surprisingly,

49 Lagerpetidae is recovered outside of Ornithodira sensu stricto, meaning that, based upon

50 current definitions at least, pterosaurs fall within Dinosauromorpha in this analysis. However,

51 fundamental ornithodiran interrelationships weren't the focus of this study and this particular

52 result should be treated with caution for now. However, these results do further highlight the

53 need for broader taxon and character sampling in phylogenetic analyses, and the effects of

54 outgroup choice on determining ingroup relationships. 


\section{INTRODUCTION}

Pterosaurs were a diverse, disparate and highly specialised group of terrestrial reptiles that represent the oldest set of vertebrates currently understood to have achieved powered flight (Benton, 1985; Unwin, 2003; Andres, 2006; Barrett et al., 2008; Andres, Clark and Xu, 2014; Britt et al., 2018). Originating at some time in either the Early or Middle Triassic (Nesbitt et al., 2017), and first appearing in the fossil record in the middle of the Late Triassic (Barrett et al., 2008; Bennet, 2013), the pterosaurs went on to thrive throughout the Mesozoic Era as one of the dominant groups of land animals, lasting right up until the very end of the Cretaceous Period and achieving a global distribution (Unwin, 2003; Dalla Vecchia, 2004; Unwin and Martill, 2007; Barrett et al., 2008; Kellner et al., 2019).

The earliest pterosaurs were generally small bodied animals, with toothed upper and lower jaws and usually an elongated tail (e.g., Padian, 1984; Hone and Benton 2007; Padian, 2008a; Padian, 2008b; Bennett, 2007; Bennet, 2014; Kellner, 2015; Britt et al., 2018; Dalla Vecchia, 2010 Dalla Vecchia, 2013; Dalla Vecchia, 2019). In addition, all known early pterosaurs appear to be fully capable of powered flight and, as yet, no transitional non-flying pterosaur taxa are known (though some specimens have been suggested to be exactly that - e.g., Huene, 
1914). Later pterosaurs went on to achieve a broader, truly global, geographic range, as well as much larger body sizes and much more unusual and often unique features of anatomy (e.g., Unwin and Bakhurina, 1994; Unwin and Bakhurina, 1995; Unwin, 2001; Unwin, 2003; Dalla Vecchia et al., 2002; Barrett et al., 2008; Hone et al., 2012; Upchurch et al., 2015; Kellner et al., 2019).

Within Pterosauria, which currently comprises the same set of taxa as the clade Pterosauromorpha (see, Nesbitt et al., 2013), there exists a number of distinct subgroups, many of which were already present in the Late Triassic. The many proposed subgroups within Pterosauria include the Eopterosauria, which is believed to comprise Preondactylia and Eudimorphodontoidea (e.g., Andres, Clark and Xu, 2014), and Macronychoptera, which comprises, inter alia, Dimorphodontidae, Anurognathidae and Pterodactyloidea (e.g., Britt et al., 2018; Dalla Vecchia, 2019)(Figure 1A-C) .

The recent phylogenetic analysis by Dalla Vecchia (2019) suggested that the earliest diverging members of Pterosauria that were considered by that study were the Preondactylia comprising Preondactylus buffarinii and Austriadactylus cristatus. This pairing of Preondactylus buffarinii and Austriadactylus cristatus concurs with the findings of Andres, Clark and Xu (2014). However, the results of these two analyses differ in that in the trees produced by Andres, Clark and $\mathrm{Xu}$ (2014), the Preondactylia form the sister-taxon to the clade comprising Peteinosaurus zambellii and Eudimorphodontoidea, a topology also supported by Upchurch et al. (2015). These clades together form Eopterosauria, a group not supported in the analysis by Britt et al. (2018) or Dalla Vecchia (2019). Equally, in the analysis by Dalla Vecchia (2019) no support was found for the clade Eudimorphodontidae (sensu Dalla, Vecchia 2014). In this respect, the 
102

103

104

105

106

analyses of Dalla Vecchia (2019) and Britt et al. (2018) also differ from each other, despite using the same dataset and having only a very small number of differences in terms of the operational taxa included (see Figure 1). This just highlights the relative instability of some of the early branching pterosaur taxa in phylogenetic analyses. Dalla Vecchia (2019) even admits that Bremer support values for many of the clades in his analysis were low.

A monophyletic Macronychoptera was found to be in a sister-taxa relationship with Peteinosaurus zambellii in the analysis of Dalla Vecchia (2019), and this unnamed clade was found as sister-taxon to another unnamed group of pterosaurs containing a number of other Late Triassic forms (Figure 1B). Unlike in the analysis by Andres, Clark and Xu (2014), Dalla Vecchia recovers Eudimorphodon ranzii within Lonchognatha, and finds no evidence for a close relationship between Eudimorphodon ranzii, Carniadactylus rosenfeldi and Arcticodactylus cromptonellus (contra Andres, Clark and Xu, 2014) (Fig 1A-B). Similarly, a close affinity between Eudimorphodon ranzii and Raeticodactylidae - which comprises Raeticodactylus filisurensis and Caviramus schesaplanensis according to Andres, Clark and Xu (2014) - was found by Britt et al. (2018) but not Dalla Vecchia (2019) (Fig 1A-C). In the reduced strict consensus tree produced in the analysis by Britt et al. (2018), the earliest diverging pterosaur clade contained a pair of taxa - Austriadraco dallavecchiai and Arcticodactylus cromptonellus - a similar result to that obtained by Kellner (2015), who named this clade Austriadraconidae (see also, Dalla Vecchia, 2009a;

Dalla Vecchia, 2009b). But again, this result differs from the analysis of both Upchurch et al. (2015) and Dalla Vecchia (2019). In an analysis by Codorniú et al. (2016), the results vary even more dramatically at the base of Pterosauira, with Anurognathidae diverging earlier within the trees recovered than either Eudimorphodon ranzii or Austriadactylus cristatus. Codorniú et al. 
124 (2016) also found evidence for a possible a Dimorphodon macronyx + Peteinosaurus zambelli

125 sister-taxon relationship, which was not recovered in any of the other analyses discussed 126 above.

It is clear from all of the differences observed between the various analyses discussed

128

130

131

132

133

134

135

136

137

138

139

140

141

142

143

144

145

above that much work still needs to be done to resolve the interrelationships between the many early pterosaur taxa currently known. The ingroup relationships of the various early pterosaur clades are unstable, as are the interrelationships between clades. However, in all the studies discussed above, there is a potential problem with the analyses in that they perhaps do not include adequate sampling from without Pterosauria - i.e., the lack of informative anatomical information from certain key outgroup taxa could be causing the poor resolution within Pterosauria.

In the analysis of Britt et al. (2018), and of other studies that utilised the same data (e.g., Codorniú et al., 2016; Dalla Vecchia, 2019), the only other ornithodiran taxa to be included in the analysis as an outgroup taxon is the unusual hypercarnivore Herrerasaurus ischigualastensis. The taxon was presumably chosen as a representative of the Dinosauria, a clade supposedly closely related to Pterosauria. However, $H$. ischigualastensis is not necessarily the best representative of the 'basal' dinosaurian condition, being a very large predator that is quite distinct in terms of its anatomy to many, if not most, of the earliest dinosaurs (see, Brusatte et al., 2010; Baron, Norman and Barrett, 2017a). In fact, the position of this taxon has proved to be highly unstable in recent times (see, Baron, Norman and Barrett, 2017b; Langer et al., 2017; Lee et al., 2019; Pacheco et al., 2019) and belongs to a wider clade of Triassic hypercarnivores that may or may not fall within Dinosauria at all (see, Baron and Williams, 
146 2018). Moreover, in the analyses by Britt et al. (2018) and Dalla Vecchia (2019), H.

147 ischigualastensis is recovered as the sister taxon to the rauisuchid paracrocodylomorph

148 Postosuchus kirkpatricki, which might suggest that character optimisation outside of the

149 pterosaurian lineage is somewhat confused and misleading. If the character distribution among

150 taxa in this analysis was fairly reflective of the topology expected to be found for these taxa, $H$.

151 ischigualastensis should, according to almost all modern phylogenetic hypotheses, fall closer to

152 the pterosaurs than to $P$. kirkpatricki. This result, while not the key focus of any of the studies

153 that recovered it, perhaps should have raised alarm bells in terms of what the data for taxa

154 immediately at the base of and just outside of Pterosauria was like. The purpose of outgroup

155 taxa is to reflect, as best as is possible, the 'basal' condition for the ingroup clade being studied

156 - it is arguable that this is not the case in the analyses by Britt et al. (2018) and Dalla Vecchia

157 (2019) and that these analyses fall short in this key respect. This omission of important

158 anatomical data may, in turn, be having a substantial adverse effect on the resolution of the

159 ingroup relationships among the numerous pterosaur taxa included in the studies.

Also missing from the datasets is a range of other close pterosaur relatives, the

anatomical characteristics of which are potentially even more helpful in determining the

ancestral state of Pterosauria than $\mathrm{H}$. ischigualastensis is when considered alone. Silesaurids,

who along with dinosaurs form the dinosauromorph clade Dracohors (Cau, 2018) are omitted, 
167 information that could be provided by the inclusion of these taxa is lost from the early

168 pterosaur phylogenetic analyses and ought to be corrected for. the outgroup taxa sampling. The analysis of Unwin (2003), for example, only used a single outgroup taxon in the form of the non-archosaurian archosauriform Euparkeria capensis. The analyses of Kellner (2003) had three outgroup taxa - Ornithosuchus longidens, Herrerasaurus ischigualastensis and Scleromochlus taylori. Of these, only one, $H$. ischigualastensis, is an ornithodiran. While Scleromochlus taylori was considered as a possible close relative of pterosaurs at the time Kellner (2003) was published, subsequent work on this taxon has demonstrated that it is more likely an archosauriform belonging to the clade Doswelliidae (see, Bennett, 2020). Finally, in the analyses of Andres, Clark and Xu (2014), the chosen outgroups were the non-avemetatarsalian archosauromorphs Euparkeria capensis and Ornithosuchus longidens, and the putative dinosaur Herrerasaurus ischigualastensis.

from analyses has had on the overall topology within Pterosauria by using a modified version of the recent dataset of Britt et al. (2018). Many of the disagreements between the recent results of Andres, Clark and Xu (2014), Upchurch et al. (2015), Kellner (2015), Britt et al. (2018) and Dalla Vecchia $(2014,2019)$ could be resolved through a simple addition of better and more appropriate outgroup taxa, and this is what this study attempts to do. By also incorporating new anatomical characters, taken from recent early dinosaur and archosaur studies, this study aims to better anchor the base of Pterosauria to a position within Avemetatarsalia and 
188 Ornithodira, so as to allow the 'basal' condition of pterosaurs to be better expressed in the 189 data.

190

191

MATERIAL AND METHODS

192

193

194

195

196

197

198

199

200

201

202

203

204

205

206

207

208

209

210

211

212

The dataset of Britt et al. (2018), as modified by Dalla Vecchia (2019), was expanded through the addition of the following taxa: Aphanosauria, Lagerpetidae, Marasuchus lilloensis, Silesauridae, Ornithischia, Theropoda and Sauropodomorpha.

Full details of each new operational taxonomic unit, which specimens were studied, and which other sources of anatomical information were used are given in Table 1.

In addition to the new taxa, 27 new anatomical characters were incorporated into the dataset of Britt et al. (2018) - five were taken from the early dinosaur dataset of Baron et al. (2017a, b), which had built upon previous works (e.g., Langer and Benton, 2006; Nesbitt, 2011), and a further nine from the archosaur dataset of Nesbitt et al. (2017). Some other characters that were added were taken from both of these studies, as they had been used in each and either entirely or partially overlapped in terms of the features that they described (chars 111116). These characters were conflated or otherwise adjusted so as to prevent repetition or over-scoring of each feature. A further three additional characters were added based upon the range of anatomical features observed in the various taxa in the study, including a simple absent/present statement for the pteroid (char. 94) to supplement character 71 of Britt et al. (2018), itself a modification from character 132 in the data of Bennett (2012). In addition, a character describing the radius to humerus ratio was added (char. 110), and a character describing the shape of the distal end of the scapula (char. 95). Four more 'classic pterosaur characteristics' were accounted for with new characters, each modified from the datasets of Vidovic and Martill (2014) and Lü et al. (2009) and were included in this study as characters 117-120. Character 99 in this analysis is a modified form of character 301 of Baron et al. (2017a) 
213 - Dorsal margin of the ilium in lateral view: 0 , sinusoidal; 1, concave (saddle-shaped), pre and

214 preacetabular and postacetabular processes upturned relative to craniocaudal centre; 2 ,

215 relatively straight or convex - state 0 has been added to describe the condition seen in

216 Macrocnemus bassanii, Postosuchus kirkpatricki and aphanosaurs. State (2) is present in

217 theropods and ornithischians, whereas state (1) describes the condition in 'basal' pterosaurs,

218 herrerasaurs, sauropodomorphs, silesaurids, lagerpetids and Marasuchus lilloensis. The full list

219 of characters added to the data matrix is given in the supplementary file.

Of the additional characters, 108 and 109 were treated as ordered, following Nesbitt (2011) and Baron et al. (2017a, b) in addition to characters 62, 74 and 91, which were also treated as ordered in the analyses of Britt et al. (2018) and Dalla Vecchia (2019).

1.5-beta (Goloboff et al., 2008), through the New technology search method. Following the

protocol of Baron et al. (2017a, b) and Nesbitt et al. (2017), memory was first set at its

maximum of 99,999, and trees were then searched for under equal weights parsimony through

a New Technology (Goloboff et al., 2008) search, with ratchet and drift set at their default

values and with 100 random additional sequences. A second search, following the protocol of

Ezcurra (2016) was then done, in which trees were searched for using a New Technology Search

(Goloboff et al., 2008) with ratchet set to 20 iterations, with five rounds of tree fusing and 100

additional sequences. The MPTs produced in this second type of analysis were then subjected

to a second round of TBR branch swapping, with a change probability of 33 and 100 additional 2017; Goloboff, 2018). 
236 This manuscript and the nomenclatural acts it contains was registered with ZooBank and the

237 manuscript assigned the following LSID: urn:Isid:zoobank.org:pub:BE350658-1D5C-456B-B129-

238 FFDE827E7DDF.

\section{RESULTS}

An initial analysis was run that excluded the additional 27 characters that were to be added to the dataset of Britt et al. (2018). This was done using equal weights and a simple New technology search. This analysis was carried out to test the effect of an expanded set of outgroup taxa alone, without the effect of added characters. The analysis produced 31 most parsimonious trees (MPTs) each of length 305 steps (Figure 2). In spite of the lack of additional characters that could help to resolve the relationships within Ornithodira and Avemetatarsalia, this analysis still recovered a monophyletic Pterosauria and generated fairly good resolution within this clade. The resolution among outgroup taxa is poor, with most outgroup taxa forming a polytomy outside of Pterosauria. Within Pterosauria there exists a 'basal' trichotomy.

Austriadactylus cristatus and Preondactylus bufarinii are recovered in a sister taxon relationship; a second 'basal' clade comprises Arcticodactylus cromptonellus, Austriadraco dallavecchiai, Seazzadactylus venieri, Carniadactylus rosenfeldi, 'Raeticodactylus' filisurensis, in the trichotomy contains Peteinosaurus zambelli, Dimorphodontidae and Lonchognatha. This result is more similar to the results of the analysis carried out by Dalla Vecchia (2019) than those of Britt et al. (2018), though this analysis has poorer resolution at the base of the pterosaur tree. The addition of new outgroups has, without the addition of new characters, 
258 generated more uncertainty about the fundamental interrelationships between the earliest

259 diverging pterosaur groups. Furthermore, the resolution between taxa in the second clade

260 produced in this analysis - the one containing Arcticodactylus cromptonellus, Austriadraco

261 dallavecchiai, Seazzadactylus venieri, Carniadactylus rosenfeldi, 'Raeticodactylus' filisurensis,

262 Caviramus schesaplanensis and specimen MCSNB 8950 - is poorer with the addition of the new

263 outgroups. In this analysis Arcticodactylus cromptonellus and Austriadraco dallavecchiai from a

264 grade leading to a polytomy containing all other taxa in this group. In the results of Dalla

265 Vecchia, on the other hand, found Seazzadactylus venieri and Carniadactylus rosenfeldi to also

266 for part of this grade leading to a smaller polytomy of Raeticodactylus' filisurensis, Caviramus

267 schesaplanensis and specimen MCSNB 8950. Within the other clades the recovered topology is

268 the same as in the analyses of Dalla Vecchia (2019) (Figure 1B). The addition of new outgroup

269 taxa alone did not result in the recovery of a monophyletic Austriadraconidae or Eopterosauria,

270 as in other previous studies (e.g. Andres, Clark and Xu (2014; Britt et al. 2018) (Figure 1A, C). By

271 adding in new characters that better resolve the relationships within Ornithodira and the

272 character optimisation at the base of Pterosauria, this uncertainty at the base of the pterosaur

273 tree was resolved and a different topology within certain constituent pterosaurian clades was

274 recovered (Figure 3).

In this first full analysis that included both the added taxa and added characters, and using equal weights and a simple New technology search, two MPTs were recovered, each of

277 length 390 steps. In the strict consensus rule tree produced from the two MPTs recovered in

278 the analysis, a monophyletic Pterosauria was found (Figure 3). This clade contains all the taxa analysed in this analysis that are traditionally considered to be pterosaurs, and together this 
280 clade forms a sister-taxon to a clade containing almost all of the newly added avemetatarsalian

281 taxa, except for Aphanosauria and Lagerpetidae. Dinosauria is recovered, as is Dracohors and

282 Dinosauriformes. Lagerpetidae is recovered without the clade containing Dinosauriformes and

283 Pterosauria. Herrerasaurus ischigualastensis, which was the only non-pterosaurian ornithodiran

284 outgroup included in the analyses of Britt et al. (2018) and Dalla Vecchia (2019), is found nested

285 within Dracohors, in a position closer to Dinosauria than to Silesauridae, as is more consistent

286 with some recent analyses of early dinosaurs (e.g., Baron and Williams, 2018).

In this full analysis, with all of the additional taxa and characters being active, the base

of the pterosaurian clade no longer contained a trichotomy. Instead, Austriadactylus cristatus

and Preondactylus bufarinii are recovered as sister-taxa, forming their own small monophyletic

group at the base of the pterosaur tree, falling outside of the clade that contains all other

pterosaurs sensu Dalla Vecchia (2019). This clade - named Preondactylia by Andres, Clark and

Xu (2014) - has also been found in a number of other studies (e.g., Upchurch et al., 2015; Britt

et al., 2018; Dalla Vecchia, 2019). Preondactylia forms the sister taxon to a clade containing two

distinct monophyletic groups: one group contains Arcticodactylus cromptonellus, Austriadraco

dallavecchiai, Seazzadactylus venieri, Carniadactylus rosenfeldi, 'Raeticodactylus' filisurensis,

Caviramus schesaplanensis and specimen MCSNB 8950; the other contains Peteinosaurus

zambelli and all other pterosaurs. This too largely agrees with the results obtained by Dalla 
302

303

304

305

306

307

308

specimen MCSNB 8950. This expanded analysis did not find such a topology within this clade.

Instead, the results recover Arcticodactylus cromptonellus, Austriadraco dallavecchiai and

Seazzadactylus venieri in their own clade, which is sister-taxon to a clade containing the others.

This first clade is akin to Austriadraconidae, as named by Kellner (2015). Austriadraconidae, in

this form, is not supported in the results presented by Dalla Vecchia, but was recovered, albeit

in a different position by Britt et al. (2018). The placement and composition of

Austriadraconidae in the results of this analysis are novel and appear to be the result of the combination of wider outgroup sampling and anatomical character choice. Within other major pterosaurian sub-clades, such as Macronychoptera, Dimorphodontidae, Anurognathidae, and

Pterodactyloidea, the topology recovered in this analysis agrees with the topology recovered in the analysis by Dalla Vecchia (2019). Moreover, this analysis found no support for the placement of Arcticodactylus cromptonellus and Austriadraco dallavecchiai in their own exclusive clade placed as sister-taxon to all other pterosaurs, as had been found by Britt et all. (2018), sensu Dalla Vecchia (2019).

\section{Further Comparisons with Previous Studies.}

While the placement of Preodactylia as the earliest diverging of the pterosaur subclades agrees with the analysis by Dalla Vecchia (2019), the result differs from Britt et al. (2018). Whereas in the taxon-reduced analyses of Britt et al. (2018), a clade containing Austriadraco dallavecchiai and Arcticodactylus cromptonellus - termed Austriadraconidae by Kellner (2015) - was found as the earliest diverging pterosaur clade, the results of Dalla Vecchia (2019) and those of the first 
323

324

325

326

analysis of this study do not provide support for such a position, but rather place the austriadraconids in a more deeply nested position. This result also differs substantially from that found by Codorniú et al. (2016) who did not find a sister-taxon relationship between Austriadactylus cristatus and Preondactylus bufarinii at all.

As stated above, the results of this first analysis support a monophyletic Austriadraconidae, sensu Kellner (2015), but, for the first time, also places Seazzadactylus venieri within it (Figure 2). In this analysis, the austriadraconids form a sister-taxon to a clade containing Carniadactylus rosenfeldi + 'Raeticodactylus' filisurensis, Caviramus schesaplanensis and unnamed specimen MCSNB 8950. Dalla Vecchia (2019) also recovered all of these taxa together into a monophyletic group, but his analysis did not recover the same interrelationships between them; Arcticodactylus cromptonellus, Austriadraco dallavecchiai and Seazzadactylus venieri form a grade leading into the clade containing Carniadactylus rosenfeldi and a trichotomy of 'Raeticodactylus' filisurensis, Caviramus schesaplanensis and MCSNB 8950 in the analysis of Dalla Vecchia (2019) (see, Figure 1A).

No close relationship is found between this group of pterosaurs and Eudimorphodon ranzii, contra the findings of Andres, Clark and Xu (2014), Upchurch et al. (2015) and Britt et al. (2018). Similarly, no support is found for the clade Eudimorphodontidae. Instead, Eudimorphodon ranzii is found within Macronychoptera and Lonchognatha, sensu Dalla Vecchia (2019).

Also consistent with the analysis of Britt et al. (2018) and of Dalla Vecchia (2019), Dimorphodon macronyx and Caelestiventus hanseni are found to be sister-taxa, forming their 
344 own clade Dimorphodontidae. This stands in contrast to the results of Codorniú et al. (2016),

345 who recovered Peteinosaurus zambelli as the sister-taxon to Dimorphodon macronyx.

Both the analyses by Britt et al. (2018) and Dalla Vecchia (2019) found a

347

348

349

350

351

352

353

354

355

356

Macronychoptera containing Dimorphodontidae and Lonchognatha, sensu Unwin 2003, and with Peteinosaurus zambelli forming the sister-taxon to Macronychoptera. This again differed from the results of Codorniú et al. (2016) who found a different position for Peteinosaurus zambelli (see above). However, despite the agreement between Britt et al. (2018) and Dalla Vecchia (2019) on the subgroups comprising Macronychoptera, the constituent taxa of Lonchognatha differed between these two analyses, with Britt et al. (2018) finding taxa such as 'Raeticodactylus' filisurensis and Caviramus schesaplanensis to be members of this more 'derived' clade (see also, Kellner, 2003). This study has not found such a construction of Lonchognatha, and instead has found a more reduced clade, sensu Dalla Vecchia (2019). Further, within Lonchognatha is a clade containing Campylognathoides and all other pterosaurs analysed in this study - i.e. a monophyletic Novialoidea sensu Kellner 2003 - and this result largely agrees with the analyses of Kellner (2003), Andres and Myers (2013), Andres, Clark and Xu (2014), Upchurch et al. (2015), Britt et al. (2018) and Dalla Vecchia (2019).

Also consistent with each of the above studies is the recovery of a monophyletic Caelidracones. However, a sister-taxon relationship between Anurognathidae and Pterodactyloidea, as recovered by Andres and Myers (2013) is not supported in this analysis. As in the analyses by Britt et al. (2018) and Dall Vecchia (2019), Caelidracones contains two clades: one containing a trichotomy of Sordes pilosus, 'ramphorynchids', and Monofenestrata, and the other containing taxa that could be loosely termed 'anurognathid types'. Again, a contrast can 
366 be drawn with the results of this analysis and the results of the analysis by Codorniú et al.

367 (2016), who placed Anurognathidae in a much more stem-ward position within Pterosauria. the taxa in this clade differ from the analyses of Britt et al. (2018) and Dall Vecchia (2019) in that Jeholopterus and Anurognathus form sister taxa, with Dendrorynchoides and weintraubi then forms the sister taxon to Anurognathidae, and this is consistent with the results of Dalla Vecchia (2019). These 'anurognathid types' together form the sister-taxon to the grouping of Sordes pilosus, the 'ramphorynchids' and monofenestratans, which is, as yet, 375 also unnamed (see Dalla Vecchia, 2019). definitions, that Pterosauria falls within Dinosauromorpha sensu Benton (1985) and not as its sister-taxon, sensu Gauthier (1986) and Nesbitt et al. (2017). Because Lagerpetidae falls outside of the clade containing Pterosauria and the grade leading into dinosaurs in this analysis, under the current definition of Dinosauromorpha - the last common ancestor of Lagerpeton chanarensis, Marasuchus lilloensis, Dinosauria and all its descendants (Benton, 1985) -

Pterosauria and, by definition, Ornithodira, would fall within Dinosauromorpha. Ornithodira would comprise Pterosauria and Dinosauriformes, rather than Pterosauria and Dinosauromorpha, as suggested in previous analyses (e.g., Langer and Benton, 2004; Nesbitt, 2011; Baron, Norman and Barrett, 2017a; Nesbitt et al., 2017). However, this position is only relatively weakly supported for now, and such interaltionships within the higher Ornithodira was not the focus of this analysis. Subsequent studies may recover more traditional topologies 
388

389

390

391

392

393

394

395

396

397

398

399

400

401

402

403

404

405

406

407

within Avemetatarsalia and composition of Ornithodira, so this study refrains from revising any definitions based upon this result alone. Within Dinosauriformes are Marasuchus lilloensis and Dracohors, sensu Cau (2018). Silesaurids form the sister-taxon to dinosaurs + herrerasaurs, sensu Baron and Williams (2018). Dinosauria in this analysis contains Ornithoscelida (see Baron, Norman and Barrett, 2017a) and Sauropodomorpha (see Baron, Norman and Barrett, 2017b).

The following is a list some of the notable nodes recovered from the base of the pterosaur tree and including Pterosauria, with all synapomorphies listed for each (Node numbers refer to numbering in Figure 3):

Node 4. Pterosauria, sensu Kellner (2003) ([Preondactylus bufarinii + Austriadactylus cristatus]/Preondactylia + [Caviramidae + Zambellisauria])

Definition: Node-based - the most recent common ancestor of the Anurognathidae, Preondactylus bufarinii and Quetzalcoatlus northropi and all their descendants (Kellner, 2003).

Character support: 7 (1-->3), 9 (0-->1), 16 (1-->2), 22 (0-->1), 39 (0-->1), 40 (0-->1), $58(0-->1), 60$ (0-->1), 70 (0-->1), 74 (0-->1), 75 (0-->1), 91 (0-->1), 94 (0-->1), $117(0-->1), 120(2-->0)$.

Remarks: The definition given by Kellner (2003) is sufficient to contain all taxa found in this analysis to be contained within the pterosaur group. As Preondactylus bufarinii, together with Austriadactylus cristatus, forms the earliest diverging clade within Pterosauria - a monophyletic Preondactylia - this definition for Pterosauria encompasses the same set of taxa as 
408 Pterosauromorpha, sensu Padian (1997). Pterosauria would, in this hypothesis, take precedence

409 over Pterosauromorpha. However, it should be worth noting that, in results that do not find

410 Preondactylia to be the earliest diverging pterosaur clade (e.g., Britt et al. 2018), Pterosauria

411 would encompass fewer taxa than Pterosauromorpha, as certain clades would fall outside of

412 the taxa encompassed by the definition for Pterosauria given by Kellner (2003). In the example

413 of Britt et al. (2018), Austriadraconidae would not be within Pterosauria but rather would be

414 non-pterosaurian pterosauromorphs, under such a regime (see below).

416 Node 5. Preondactylia, sensu Andres, Clark and Xu (2014) (Preondactylus bufarinii +

417 Austriadactylus cristatus)

418 Definition: The least inclusive clade that includes Preondactylus bufarinii and Austriadactylus

419 cristatus.

420 Character support: $11(0-->1), 48(0-->1), 49(0-->1)$.

421 Remarks: Often found to be the earliest diverging members of Pterosauria (e.g., Dalla Vecchia

422 2019), or early diverging members of 'Eopterosauria' (e.g., Andres, Clark and Xu, 2014;

423 Upchurch et al., 2015), this small clade is fairly consistently recovered among early pterosaur

424 cladistic studies, with the notable exception of Codorniú et al. (2016).

425

426 Unnamed clade (Caviramidae + Zambellisauria)

427 Character support: 45 (1-->0), 47 (1-->0), 77 (0-->1), 95 (0-->1). 
428 Remarks: This clade contains all pterosaur taxa except for the clade containing Preondactylus

429 bufarinii + Austriadactylus cristatus i.e., all pterosaurs more 'derived' than Preondactylia. This 430 clade has consistently been found among studies (e.g., Codorniú et al., 2016; Britt et al., 2018;

431 Dalla Vecchia, 2019), although the placement of certain taxa within this clade varies, for

432 example in the results of Britt et al. (2018), this clade does not contain Arcticodactylus

433 cromptonellus and Austriadraco dallavecchiai (see Figure 1C). It may prove necessary in the

434 future to erect a stem-based clade to contain all taxa more closely related to, as an example,

435 Quetzalcoatlus northropi than to Preondactylus bufarinii.

Node 7: Caviramidae (new clade)

Definition: Node-based - the least inclusive clade that includes Arcticodactylus cromptonellus and Caviramus schesaplanensis (new).

Etymology: For Caviramus schesaplanensis - one of two anchoring member taxa used in the node-based definition for the clade, as outlined above.

Character support: $3(0-->1)$, a skull that is curved down caudally; $12(0-->1)$, a jugal process of the maxilla that is subtrapezoidal, tapering to a point only distally, and a proximal part with parallel dorsal and ventral margins; $43(0-->1)$, a dentition that has tri- to quinticuspid tooth

445 crowns; $81(0-->1)$, a wing phalanx two that is as long as the ulna.

446 Remarks: This clade has been recovered in the recent analysis of Dalla Vecchia (2019) and is

447 also supported in the first analysis of this study by a number of shared anatomical character 
448 states, or synapomorphies (see above). The topology within the clade varies between the

449 analyses of Dalla Vecchia (2019) and this study, but both find the same set of taxa and

450 specimens to fall within it. This early diverging subgroup contains within it the austriadraconids

451 of Kellner (2015) and a handful of other Triassic taxa and specimens, including the as yet

452 unnamed MCSNB 8950, which has previously been the source of phylogenetic uncertainty in

453 other studies (see Britt et al., 2018). This clade is the least consistently supported among the

454 various analyses of this study and this is discussed further below. However, it is worth noting

455 that the clade was found in both the analysis that used only new outgroup taxa but no new

456 characters and the analysis that used both. The internal topology differed between these two

457 analyses, as did the position of the clade within Pterosauria, but the constituent taxa was

458 consistent, and consistent with the results of Dalla Vecchia (2019).

Node 6. Austriadraconidea, sensu Kellner (2015) (Arcticodactylus cromptonellus + Austriadraco

461

dallavecchiai + Seazzadactylus venieri)

462

Definition: The least inclusive clade that includes Arcticodactylus cromptonellus and

463 Austriadraco dallavecchiai, sensu Kellner (2015).

464 Character support: 103 (1-->0), $120(0-->1)$.

465 Remarks: This clade was named by Kellner (2015), but was not supported in a number of other

466 recent analyses of early pterosaurs (e.g., Andres, Clark and Xu, 2014; Upchurch et al., 2015).

467 However, this close relationship was found in the more recent analyses of Britt et al. (2018),

468 who recovered the clade as the earliest diverging within Pterosauria, and then Dalla Vecchia

Peer] reviewing PDF | (2020:03:47010:1:1:NEW 12 Jun 2020) 
469 (2019), who, like this study, found the clade to be slightly more 'derived'. Unlike either of the

470 aforementioned studies, this study has found that the clade also contains Seazzadactylus

471 venieri; as in the analysis of Dalla Vecchia (2019) this grouping of taxa fall within a larger clade

472 of early-diverging pterosaur taxa (here named as Caviramidae, clade nov.).

474 Unnamed clade (Carniadactylus rosenfeldi + 'Raeticodactylus' filisurensis, Caviramus

475 schesaplanensis + MCSNB 8950)

476 Character support: $11(0-->2), 21(0-->1), 65(0-->1), 76,(0-->1), 80(0-->1)$.

477 Remarks: This clade was also recovered in the analysis by Dalla Vecchia (2019) and contained 478 the same taxa and the same internal topology.

Node 8. Zambellisauria (new clade) (Peteinosaurus zambelli + Macronychoptera)

481

482

Definition: Node-based - the least inclusive clade that includes Peteinosaurus zambelli, Dimorphodon macronyx, Pterodactylus antiquus and Quetzalcoatlus northropi (new).

Etymology: The clade name honours Rocco Zambelli, curator of the Bergamo natural history museum, for whom Peteinosaurus zambelli was named; $P$. zambelli being one of the two taxa chosen as an anchor in this cladistic definition, . Zambelli (1973) also named Eudimorphodon ranzii, a well-known and important early pterosaur and putative member of Zambellisauria (see Andres, Clark and Xu, 2014; Britt et al., 2018; Dalla Vecchia, 2019). 
488 Character support: $56(0-->1)$, more than three sacral vertebrae; 59 (0-->1), filiform processes of 489 the caudal zygapophyses present in caudal vertebrae.

490 Remarks: This clade is consistently recovered by most modern analyses (e.g., Britt et al. 2018, 491 Dalla Vecchia, 2019) and in all of the analyses in this study, regardless of the optimality criteria 492 used in searching for trees in the analyses, and both with and without the inclusion of the new 493 anatomical characters. Such a clade was not found in the analysis of Andres, Clark and Xu 494 (2014), who instead placed Peteinosaurus zambelli as sister-taxon to Eudimorphodontoidae, 495 within a monophyletic Eopterosauria - a hypothesis that has fallen out favour in more recent 496 studies and is not supported in any of the analyses carried out in this study.

Node 9. Macronychoptera (Dimorphodontidae + Lonchognatha)

Character support: 63 (1->2), $64(0->1), 65(0->1)$

Node 10. Dimorphodontidae (Dimorphodon macronyx + Caelestiventus hanseni) (0-->1), 48 (0-->1), 52 (0-->1), 96 (1-->0), 118 (1-->2).

Remarks: As in the analyses of Britt et al. (2018) and Dalla Vecchia (2019), this study finds a 


\section{Node 11. Lonchognatha}

508 Character support: $70(1-->2), 80(0-->2), 88(0-->1)$

509 Remarks: The composition of Lonchognatha and its possible sister-taxon relationship with

510 Dimorphodontidae has been fairly consistently recovered in recent analyses (Britt et al., 2018;

511 Dalla Vecchia, 2019), although other studies have placed Lonchognatha within Novialoidae

512 (e.g., Andres, Clark and Xu, 2014). This second hypothesis is not recovered in all but one of the

513 analyses of this study. That is to say, in only one analysis does this study find

514 Campylognathoides to be 'less derived' than Eudimorphodon species (see below).

In the second full analysis, utilising both the new taxa and new anatomical characters,

TBR branch swapping after a differently configured New Technology search produced 2 MPTs, each also of length 390 steps. However, in this analysis, the resolution in this tree was greatly reduced (Figure 4A). While Aphanosauria and Lagerpetidae were still found outside of

520 Ornithodira, and the monophyly of and interrelationships within Dinosauriformes remained consistent with previous analyses, in this second full analysis, the interrelationships between

522 the groups within Pteorsauria was not clearly resolved - although monophyletic

523 Austriadraconidae and Novialoidea were both found again. The large polytomy at the base of

524 Pterosauria is more reminiscent of the full-taxon-sample analysis carried out using TNT by Britt 525 et al. (2018). As in Britt et al. (2018), the specimen MCSNB 8950 was removed as a wildcard

526 taxon and the analysis re-run. In this reduced analysis, a single tree was recovered (Figure 4B).

527 In this tree, Austriadraconidae is once again recovered as monophyletic, as in the first analysis 
528 of this study and the second full-taxon-range analysis with TBR. However, in the reduced

529 second analysis, but unlike in the full second analysis, Austriadraconidae contains

530 Seazzadactylus venieri. This is similar to the result obtained in the first analysis, although the

531 position of Austriadraconidae is different in both the reduced and full second analyses

532 (compare Figure 3 and Figure 4B).

Finally, in the implied weights analyses, the topology within Pterosauria differed from

534 the first and second analyses (Figure 5A-B). Only one tree was produced in each of three

535 analyses, with lengths of $37.03690,27.65440$, and 17.04634 for $k=3,5$ and 10 respectively. In

536 the first two of these analyses ( $k=3$ and 5 ), the earliest diverging clade of pterosaurs are the

537 Austriadraconidae - however, this clade was not found to contain Seazzadactylus venieri in this

538 analysis. The clade made up of Austriadactylus cristatus and Preondactylus buffarini, named

539 above as Preondactylidae, then forms the sister-taxon of the clade of Peteinosaurus zambelli +

540 Macronychoptera, named above as Zambellisauria. In searches with $\mathrm{k}$ at or above 10 however,

541 the structure of the tree once again changes, with the preondactylids once again falling out as

542 the most stem-ward of the clades in Pterosauria and, as in some of the previous analyses of this

543 study, Austriadraconidae was found to contain Seazzadactylus venieri (Figure 5B). Caviramidae

544 was not supported in any of these analyses, whereas Zambellisauria was consistently recovered

545 in each. Likewise, clades such as Dimorphodontidae, Lonchognatha, Novialoidea, Caelidracones,

546 Monofenestrata, Pterodactyloidea, and Anurognathidae were all found to be largely consistent

547 through the various implied weights parsimony analyses. The taxon referred to as

548 'Dimorphodon' weintraubi was recovered closer to Sordes pilosus and the monofenestratans

549 than to Anurognathidae in the lower weighted implied weights analyses, but closer to 
550 Anurognathidae in analyses with a $\mathrm{k}$ value $=10$ or more. In all the implied weights analyses, the

551 'ramphorynchids' we found to be more closely related to Monofenestrata than to Sordes

552 pilosus, which was recovered as the sister-taxon to the clade of Monofenestrata + the

553 'ramphorynchids' (Figure 5A-B).

$554 \quad$ The largest difference in the arrangement of taxa between the implied weights analyses

555 for $k<10$ and for $k=10$ or more is the composition of Zambellisauria. In all the analyses

556 Zambellisauria is recovered as monophyletic, but in the lower k value analyses, contains, inter

557 alia, Seazzadactylus venieri, Carniadactylus rosenfeldi, 'Raeticodactylus' filisurensis, Caviramus

558 schesaplanensis and the specimen MCSNB 8950, whereas in analyses with $\mathrm{k}=10$ or more, these

559 five operational taxonomic unites were recovered outside of Zambellisauria (see Figure 5A-B).

560 These differences in topology between the results of the various implied weights parsimony

561 analyses suggests that certain anatomical characters in the dataset are broadly distributed

562 across the taxa whilst also being important for uniting certain clades - as the implied weighting

563 factor is increased, the weight of characters that could support the monophyly of clades such as

564 Caviramidae (see above), or support a 'basal' position for Austriadraconidae, are being reduced

565 by the search programme because these characters appear to be more homoplastic. However,

566 these effects may be reduced by the further addition of anatomical characters as the dataset is

567 expanded upon in subsequent studies.

568

569

DISCUSSION

Peer] reviewing PDF | (2020:03:47010:1:1:NEW 12 Jun 2020) 
570 It is clear from the variability in the results of the analyses in this study alone that the

571 phylogenetic position of certain early pterosaur clades is still highly unstable, even with better

572 taxon and character sampling. When analysed using certain methods, the addition of more

573 avemetatarsalian taxa and new characters provided further support for certain clades and

574 helped to revolve interrelationships between genera within some subclades. In addition, this

575 expanded analysis changed the composition of some recognised clades, from example

576 Austriadraconidae, which was, in analysis one, found to also include the recently described

577 Seazzadactylus venieri for the first time. Choice of taxa and anatomical characters clearly has

578 had some effect on the interrelationships of the ingroup pterosaur taxa, as has also been

579 demonstrated to be the case in early studies of dinosaur (e.g., Müller and Dias-da-Silva, 2019).

580 This study has taken steps to address the under-sampling from closely related ornithdiran

581 clades in previous pterosaur studies, but much work needs to be done to further broaden the

582 datasets used in phylogenetic analyses, in terms of both the operational taxa and anatomical

583 characters and character states.

What this study has also demonstrated is how using different approaches to phylogenetic analysis can produce substantially different results when it comes to the interrelationships within Pterosauria. The earliest diverging clade of pterosaurs has been found to be either the Preondactylia (in analysis one and in implied weights analyses for $k=10$ or more), or Austriadraconidae (when using TBR branch swapping or implied weights with $\mathrm{k}<10$ ). throughout the various analyses of this study, and many too have been supported in previous analyses (Andres, Clark and Xu, 2014; Britt et al., 2018; Dalla Vecchia, 2019). This would suggest 
592 that the evidence is increasingly supporting the validity of such monophyletic subsets within

593 Pterosauria, and these should, for the sake of stability and clarity in future research, be defined

594 and, if not already so, named. This study has erected two clades for these purposes.

595 Zambellisauria is erected to contain all pterosaur taxa descended from the most recent

596 common ancestor of Peteinosaurus zambellii and the various members of Macronychoptera.

597 This clade is now consistently recovered in most phylogenetic analyses and is strongly

598 supported in the results of these analyses. Should Peteinosaurus zambellii be recovered in a

599 much more stem-ward position in the future, for example if future analyses resurrect

600 Eopterosauria, with Peteinosaurus zambellii contained within it, the definition for

601 Zambelliasauria would then encompass the same set of taxa as Pterosauria and, as a result,

602 would become obsolete. However, in the emerging consensus on early pterosaur relationships

603 in this part of the tree, the clade Zambellisauria remains well-supported and distinct for now.

604 Under the definition given for Caviramidae, as also given above, in scenarios in which a

605 distinct monophyletic group is found to be more 'derived' than Preondactylia but outside of the

606 clade containing all other, more 'derived' pterosaurs (see Figure 3), the name would be distinct

607 and valid. However, in scenarios such as presented in the results of the second and third

608 analyses, or in other studies (e.g., Britt et al., 2018) the clade Caviramidae would contain the

609 same taxa as Pterosauria and therefore become obsolete. However, the validity of Caviramidae

610 is not dependent on the position taxa such as Peteinosaurus zambellii and Eudimorphodon

611 ranzii, which have a tendancy to 'bounce around' the tree, so long as the Autriadraconids are

612 not found to be either more or less 'derived' than the small clade containing Carniadactylus

613 rosenfeldi, 'Raeticodactylus' filisurensis, and Caviramus schesaplanensi. It is only in hypotheses 
614 in which Austriadraconids fall as the earliest diverging members of Pterosauria (e.g., analysis

615 two of this study; Britt et al., 2018), or are paraphyletic (e.g., Codorniú et al., 2016), that

616 Caviramidae would be invalid as a distinct clade.

617

It would also appear from the results of these analyses, and other recent works, that the

618

619

620

621

622

623

624

625

626

627

628

higher-level interrelationships between pterosaur taxa are becoming more stabilised. Clades

such as Dimorphodontidae, Lonchognatha, Novialoidea, Caelidracones, Monofenestrata,

Pterodactyloidea, and Anurognathidae are all consistently found in these analyses, and only the composition of each varies a little between them. In particular Eudimorphodon ranzii is a

particularly difficult taxon in terms of its position, having been recovered in a range of 'derived' and more 'basal' positions within the tree, in the both the analyses of this study and previous recent studies. With the addition of more taxa and more characters, and as more phylogenetic analysis techniques are turned on the question of pterosaur systematics, such problems of placing difficult to classify taxa may yet be resolved.

Pterosaur interrelationships have been shown to vary between analyses, with the fundamental interrelationships that are recovered being dependant upon the method of analysis, the character choice and taxon choice. The addition of more appropriate avemetatarsalian outgroup taxa to the early pterosaur dataset of Britt et al. (2018) made a difference in the overall topologies recovered within the various pterosaur clades, and to the fundamental structure of the pterosaur tree. However, a more dramatic change in result could be achieved 
635 through the use of different phylogenetic analysis techniques, such and implied weights

636 parsimony. While some pterosaur clades have proven to be stable throughout the various

637 analyses, others have not, particularly those that fall most stem-ward on the tree. More needs

638 to be done to resolve this issue, but wider character and taxon sampling in the future would be

639 an important first step. Additional, utilisation of a wider range of phylogenetic analysis

640 techniques should be adopted to test the strength of hypotheses of early pterosaur

641 interrelationships as more taxa and character states are added.

\section{REFERENCES}

Andres BB. 2006. The earliest pterosaurs. Journal of Vertebrate Paleontology 26(3):37A.

Andres BB, Clark J, Xu X. 2014. The Earliest Pterodactyloid and the Origin of the Group. Current Biology. 24 (9): 1011-6. doi:10.1016/j.cub.2014.03.030.

Baron MG, Williams ME. 2018. A re-evaluation of the enigmatic dinosauriform Caseosaurus crosbyensis from the Late Triassic of Texas, USA and its implications for early dinosaur evolution. Acta Palaeontologica Polonica. 63 (1): 129-145 doi:10.4202/app.00372.2017

650 Baron MG, Norman DB, and Barrett PM. 2017a. A new hypothesis of dinosaur relationships and 651 early dinosaur evolution. Nature, 543: 501-506. doi:10.1038/nature21700

652 Baron MG, Norman DB, Barrett PM. 2017b. Untangling the dinosaur family tree: a rebuttal. 653 Nature. 551:E4-E5.

654 Baron MG, Norman DB, Barrett PM. 2017c. Postcranial anatomy of Lesothosaurus diagnosticus 655 (Dinosauria: Ornithischia) from the Lower Jurassic of southern Africa: implications for basal 656 ornithischian taxonomy and systematics. Zoological Journal of the Linnean Society 179(1):125657168

658 Barrett PM, Butler RJ, Yates AM, Baron MG, Choiniere JN. 2016. New specimens of the basal 659 ornithischian dinosaur Lesothosaurus diagnosticus Galton, 1978 from the Early Jurassic of South 660 Africa. Palaeontologia Africana 50:48-63.

661 Barrett PM, Butler RJ, Edwards NP, Milner AR. 2008. Pterosaur distribution in time and space: 662 an atlas. Zitteliana B28:61-107. 
663 Bennett SC. 2007. A second specimen of the pterosaur Anurognathus ammoni.

664 Paläontologische Zeitschrift 81(4):376-398.

665 Bennett SC. 2013. The phylogenetic position of the Pterosauria within the Archosauromorpha 666 reexamined. Historical Biology 25(22), 545-563.

667 Bennett SC. 2014. A new specimen of the pterosaur Scaphognathus crassirostris, with 668 comments on constraint of cervical vertebrae number in pterosaurs. Neues Jahrbuch für 669 Geologie und Paläontologie Abhandlungen 271(3):327-348.

670 Bennett SC. 2020. Reassessment of the Triassic archosauriform Scleromochlus taylori: neither 671 runner nor biped, but hopper. PeerJ 8:e8418 https://doi.org/10.7717/peerj.8418.

672 Benton MJ. 1985. Classification and phylogeny of the diapsid reptiles. Zoological Journal of the 673 Linnean Society 84:97-164.

674 Butler RJ. 2005. The 'fabrosaurid' ornithischian dinosaurs of the Upper Elliot Formation (Lower 675 Jurassic) of South Africa. Zoological Journal of the Linnean Society 145:175-218.

676 Butler RJ. 2010. The anatomy of the basal ornithischian dinosaur Eocursor parvus from the 677 lower Elliot Formation (Late Triassic) of South Africa. Zoological Journal of the Linnean Society 678 160:648-684.

679 Butler RJ, Smith R, Norman DB. 2007. A primitive ornithischian dinosaur from the Late Triassic 680 of South Africa and the early evolution and diversification of Ornithischia. Proceedings of the 681 Royal Society B 274:2041-2046.

682 Butler RJ, Porro LB, Norman DB. 2008. A juvenile skull of the primitive ornithischian dinosaur 683 Heterodontosaurus tucki from the 'Stormberg' of southern Africa. Journal of Vertebrate 684 Paleontology 28:702-711.

685 Britt BB, Dalla Vecchia FM, Chure DJ, Engelmann GF, Whiting MF, Scheetz RD. 2018.

686 Caelestiventus hanseni gen. et sp. nov. extends the desert-dwelling pterosaur record back 65 687 million years. Nature Ecology \& Evolution 2(9):1386-1392.

688 Brusatte SL, Nesbitt SJ, Irmis RB, Butler RJ, Benton MJ, Norell MA. 2010. The origin and early 689 radiation of dinosaurs. Earth-Science Reviews 101(1), 68-100.

690 Cau A. 2018. The assembly of the avian body plan: a 160-million-year long process. Bollettino 691 della Società Paleontologica Italiana. 57 (1): 1-25. doi:10.4435/BSPI.2018.01.

692 Codorniú L, Paulina Carabajal A, Pol D, Unwin D, Rauhut OW. 2016. A Jurassic pterosaur from 693 Patagonia and the origin of the pterodactyloid neurocranium. PeerJ. 2016;4:e2311.

694 doi:10.7717/peerj.2311.

695 Dalla Vecchia FM. 2004 A review of the Triassic pterosaur record. Rivista del Museo Civico di 696 Scienze Naturali “E. Caffi”, Bergamo 22(2003):13-29. 
697 Dalla Vecchia FM. 2009a. Anatomy and systematics of the pterosaur Carniadactylus gen. $\mathrm{n}$. 698 rosenfeldi (Dalla Vecchia, 1995) Rivista Italiana di Paleontologia e Stratigrafia 115(2):159-186.

699 Dalla Vecchia FM. 2009b. The first Italian specimen of Austriadactylus cristatus (Diapsida, 700 Pterosauria) from the Norian (Upper Triassic) of the Carnic Prealps. Rivista Italiana di 701 Paleontologia e Stratigrafia 115(3):291-304.

702

703

704

705

706

707

708

709

710

711

712

713

714

715

716

717

718

719

720

721

722

723

724

725

726

727

728

Dalla Vecchia FM. 2010. A new pterosaur from the upper Triassic of northeastern Italy. Acta Geoscientica Sinica 31(supp 1):17.

Dalla Vecchia FM. 2013. Triassic pterosaurs. In: Nesbitt SJ, Desojo JB, Irmis RB, eds. Anatomy, Phylogeny and Palaeobiology of Early Archosaurs and their Kin. London: Geological Society London, Special Publication. 379:119-155.

Dalla Vecchia FM. 2014. Gli pterosauri triassici. Udine: Museo Friulano di Storia Naturale. 54:319 Pubblicazione del Museo Friulano di Storia Naturale

Dalla Vecchia FM. 2019. Seazzadactylus venieri gen. et sp. nov., a new pterosaur (Diapsida: Pterosauria) from the Upper Triassic (Norian) of northeastern Italy. PeerJ 7:e7363 https://doi.org/10.7717/peerj.7363.

Dalla Vecchia FM, Wild R, Hopf H, Reitner J. 2002. A crested rhamphorhynchoid pterosaur from the Late Triassic of Austria. Journal of Vertebrate Paleontology 22(1):196-199.

Dzik J 2003. A beaked herbivorous archosaur with dinosaur affinities from the early Late Triassic of Poland. Journal of Vertebrate Paleontology. 23 (3): 556-574. doi:10.1671/a1097.

Ezcurra MD. 2016. The phylogenetic relationships of basal archosauromorphs, with an emphasis on the systematics of proterosuchian archosauriforms. PeerJ 4:e1778 doi.org/10.7717/peerj.1778.

Galton PM. 2014. Notes on the postcranial anatomy of the heterodontosaurid dinosaur Heterodontosaurus tucki, a basal ornithischian from the Lower Jurassic of South Africa. Revue de Paléobiologie, Genève. 1. 33: 97-141.

Gauthier JA. 1986. Saurischian monophyly and the origin of birds. The Origin of Birds and the Evolution of Flight, K. Padian (ed.), Memoirs of the California Academy of Sciences 8:1-55.

Goloboff PA, Farris JS, Nixon K. 2008. TNT, a free program for phylogenetic analysis. Cladistics 24, 774-786. doi:10.1111/j.1096-0031.2008.00217.

Hone DWE, Benton MJ. 2007. An evaluation of the phylogenetic relationships of the pterosaurs among archosauromorph reptiles. Journal of Systematic Palaeontology, 5, 465-469. 
729 Hone DWE, Tischlinger H, Frey E, Röper M. 2012. A new non-pterodactyloid pterosaur from the 730 Late Jurassic of Southern Germany. PLOS ONE 7(7):e39312.

731 Huene Fv. 1914. Beiträge zur Geschichte der Archosaurier. Geologische und paläontologische 732 Abhandungen, NF 13:3-53.

733 Irmis, RB, Nesbitt SJ, Padian K, Smith ND, Turner AH, Woody D, Downs A. 2007. A Late Triassic dinosauromorph assemblage from New Mexico and the rise of dinosaurs. Science. 317 (5836): 358-361. doi:10.1126/science.1143325.

736

Kellner AWA. 2003. Pterosaur phylogeny and comments on the evolutionary history of the group. In: Buffetaut E, Mazin J-M, eds. Evolution and Palaeobiology of Pterosaurs. London: Geological Society London, Special Publication. 217:105-137

Kellner AWA. 2015. Comments on Triassic pterosaurs with discussion about ontogeny and description of new taxa. Anais da Academia Brasileira de Ciências 87(2):669-689.

Kellner AWA, Rodrigues T, Costa FR, Weinschütz LC, Figueiredo RG, Souza GA, Brum AS, Eleutério LHS, Mueller CW, Sayão JM. 2019. Pterodactyloid pterosaur bones from Cretaceous deposits of the Antarctic Peninsula. Anais da Academia Brasileira de Ciências 91: e20191300. DOI 10.1590/0001-3765201920191300.

Knoll F. 2002a. Les fabrosauridae Galton, 1972. (Dinosauria: Ornithischia): répartition géographique et stratigraphique; systématique et phylogénie. Paris: Muséum national d'Histoire naturelle. (Vol. 1) Pp. 243 +(Vol. 2) 71 pl

Knoll F. 2002b. Nearly complete skull of Lesothosaurus (Dinosauria: Ornithischia) from the Upper Elliot Formation (Lower Jurassic: Hettangian) of Lesotho. Journal of Vertebrate Paleontology 22(2):238-243

Knoll F. 2002c. New skull of Lesothosaurus (Dinosauria: Ornithischia) from the Upper Elliot Formation (Lower Jurassic) of southern Africa. Geobios 35:595-603.

Langer MC. 2003. The pelvic and hind limb anatomy of the stem-sauropodomorph Saturnalia tupiniquim (Late Triassic, Brazil). PaleoBios, 23(2):1-40.

Langer MC, Benton MJ. 2006. Early dinosaurs: a phylogenetic study. Journal of Systematic Palaeontology 4:309-358.

Langer MC, Abdala F, Richter M, Benton MJ. 1999. A sauropodomorph dinosaur from the Upper Triassic (Carnian) of southern Brazil. Comptes Rendus de I'Académie des Sciences, 329: 511 517.

Langer MC, Ezcurra MD, Rauhut OWM, Benton MJ, Knoll F, McPhee BW, Novas FE, Pol D, Brusatte SL. 2017. Untangling the dinosaur family tree. Nature 551 (7678): E1-E3. doi:10.1038/nature24011.Müller RT, Dias-da-Silva S. 2019. Taxon sample and character coding 
763

764

765

766

767

768

769

770

771

772

773

774

775

776

777

778

779

780

781

782

783

784

785

786

787

788

789

790

791

792

793

794

795

796

deeply impact unstable branches in phylogenetic trees of dinosaurs, Historical Biology, 31:8, 1089-1092, doi:10.1080/08912963.2017.1418341.

Lee MSY, Baron MG, Norman DB, Barrett PM. 2019. Dynamic biogeographic models and dinosaur origins. Earth Environmental Science Transactions of the Royal Society of Edinburgh Vol. 109, Issue 1-2 (Fossils, Function and Phylogeny: Papers on Early Vertebrate Evolution in Honour of Professor Jennifer A. Clack), 325-332 doi:10.1017/S1755691018000920.

Lü JC, Azuma Y, Dong ZM, Barsbold R, Kobayashi Y, Lee YN. 2009 New material of dsungaripterid pterosaurs (Reptilia: Pterosauria) from western Mongolia and its paleoecological implications. Geol. Mag. 146, 690-700. doi:10.1017/S0016756809006414.

Martínez RN, Sereno PC, Alcober OA, Colombi CE, Renne PR, Montañez IP, Currie BS. 2011. A basal dinosaur from the dawn of the dinosaur era in southwestern Pangaea. Science 331:206210.

Martínez RN, Apaldetti C, Correa GA, Abelín D. 2016. A Norian lagerpetid dinosauromorph from the Quebrada del Barro Formation, northwestern Argentina. Ameghiniana. 53 (1): 1-13. doi:10.5710/AMGH.21.06.2015.2894

Martz JW, Small BJ. 2019. Non-dinosaurian dinosauromorphs from the Chinle Formation (Upper Triassic) of the Eagle Basin, northern Colorado: Dromomeron romeri (Lagerpetidae) and a new taxon, Kwanasaurus williamparkeri (Silesauridae) PeerJ 7:e7551 https://doi.org/10.7717/peerj.7551.

Müller RT, Dias-da-Silva S. 2019. Taxon sample and character coding deeply impact unstable branches in phylogenetic trees of dinosaurs, Historical Biology, 31:8, 1089-1092, DOI: 10.1080/08912963.2017.1418341.

Nesbitt SJ. 2011. The Early Evolution of Archosaurs: Relationships and the Origin of Major Clades. Bulletin of the American Museum of Natural History 352: 1-292.

Nesbitt SJ, Irmis RB, Parker WG, Smith ND, Turner AH, Rowe T. 2009a. Hindlimb osteology and distribution of basal dinosauromorphs from the Late Triassic of North America. Journal of Vertebrate Paleontology. 29 (2): 498-516. doi:10.1671/039.029.0218.

Nesbitt SJ, Smith ND, Irmis RB, Turner AH, Downs A, Norell MA. 2009b. A complete skeleton of a Late Triassic saurischian and the early evolution of dinosaurs. Science, 326 (5959): 1530-1533, doi:10.1126/science.1180350.

Nesbitt SJ, Sidor CA, Irmis RB, Angielczyk KD, Smith RMH, Tsuji LA. 2010 Ecologically distinct dinosaurian sister group shows early diversification of Ornithodira. Nature 464(7285):95-8.

Nesbitt SJ, Desojo JB, Irmis RB. 2013. Anatomy, Phylogeny and Palaeobiology of Early Archosaurs and Their Kin. Geological Society of London. 
797 Nesbitt SJ, Butler RJ, Ezcurra MD, Barrett PM, Stocker MR, Angielczyk KD, Smith RMH, Sidor CA, 798 Niedźwiedzki G, Sennikov AG, Charig AJ. 2017. The earliest bird-line archosaurs and the 799 assembly of the dinosaur body plan. Nature. 544 (7651): 484-487 doi:10.1038/nature22037.

800 Nesbitt SJ, Butler RJ, Ezcurra MD, Charig AJ, Barrett PM. 2018 The anatomy of Teleocrater 801 rhadinus, an early avemetatarsalian from the lower portion of the Lifua Member of the Manda 802 Beds (Middle Triassic). J. Vertebr. Paleont. 37(Supp. 1), 142-177. doi:10.1080/ $803 \quad 02724634.2017 .1396539$.

804

805

806

807

808

809

810

811

812

813

814

815

816

817

818

819

820

821

822

823

824

825

826

827

828

829
Norman DB, Crompton AW, Butler RJ, Porro LB, Charig AJ. 2011. The Lower Jurassic ornithischian dinosaur Heterodontosaurus tucki Crompton \& Charig, 1962: Cranial anatomy, functional morphology, taxonomy, and relationships. Zoological Journal of the Linnean Society: 182-276. doi:10.1111/j.1096-3642.2011.00697.x.

Pacheco C, Müller RT, Langer MC, Pretto FA, Kerber L, Dias da Silva SD. 2019. Gnathovorax cabreirai: a new early dinosaur and the origin and initial radiation of predatory dinosaurs. PeerJ. doi:10.7717/peerj.7963.

Padian K. 1984. Pterosaur remains from the Kayenta Formation (Early Jurassic) of Arizona. Palaeontology 27:407-413.

Padian K. 1997. Pterosauromorpha. In P.J. Currie and K. Padian (editors), Encyclopedia of dinosaurs: 617-618. San Diego: Academic Press.

Padian K. 2008a. The Early Jurassic pterosaur Dorygnathus banthensis (Theodori, 1830) Special Papers in Palaeontology 80:1-64

Padian K. 2008b. The Early Jurassic pterosaur Campylognathoides Strand, 1928. Special Papers in Palaeontology 80:65-107

Parry LA, Baron MG, Vinther J. 2017. Multiple optimality criteria support Ornithoscelida. Royal Society open science:4170833. doi.org/10.1098/rsos.170833.

Porro LB, Witmer LM, Barrett PM. 2015. Digital preparation and osteology of the skull of Lesothosaurus diagnosticus (Ornithischia: Dinosauria) PeerJ 3:e1494.

Sereno PC, Martínez RN, Alcober OA. 2013. Osteology of Eoraptor lunensis (Dinosauria, Sauropodomorpha). Basal sauropodomorphs and the vertebrate fossil record of the Ischigualasto Formation (Late Triassic: Carnian-Norian) of Argentina. Journal of Vertebrate Paleontology. Memoir. 12: 83-179. doi:10.1080/02724634.2013.820113.

Unwin DM. 2001. An overview of the pterosaur assemblage from the Cambridge Greensand (Cretaceous) of Eastern England. Mitteilungen aus dem Museum fur Naturkunde in Berlin, Geowissenschaftliche Reihe 4: 189-221. 
830 Unwin DM. 2003. On the phylogeny and evolutionary history of pterosaurs. In: Buffetaut E, 831 Mazin J-M, eds. Evolution and Palaeobiology of Pterosaurs. London: Geological Society London, 832 Special Publication. 217:139-190.

833 Unwin DM, Bakhurina NN. 1994. Sordes pilosus and the nature of the pterosaur flight 834 apparatus. Nature 371, 62-64. https://doi.org/10.1038/371062a0.

835 Unwin DM, Bakhurina NN. 1995. Wing shape in pterosaurs. Nature 374: 315-316.

836 Unwin DM, Martill DM. 2007. Pterosaurs of the Crato Formation. In: D.M. Martill, G. Bechly, 837 and R.F. Loveridge (eds.), The Crato Fossil Beds of Brazil, 475-524. Cambridge University Press, 838 Cambridge.

839 Upchurch P, Andres B, Butler RJ, Barrett PM. 2015. An analysis of pterosaurian biogeography: 840 implications for the evolutionary history and fossil record quality of the first flying vertebrates. 841 Historical Biology 27, 697-717.

842 Vidovic SU, Martill DM. 2014. Pterodactylus scolopaciceps Meyer, 1860 (Pterosauria, 843 Pterodactyloidea) from the Upper Jurassic of Bavaria, Germany: The Problem of Cryptic

844 Pterosaur Taxa in Early Ontogeny. PLoS ONE 9(10): e110646.

845 doi.org/10.1371/journal.pone.0110646.

846 Zambelli R. 1973. Eudimorphodon ranzii gen. nov., sp. nov., uno pterosauro triassico. Istituto

847 Lombardo-Academia di Scienze e Lettere (Rendiconti di Scienze) B 107:27-32.

848

849

850

851

852

853

Figures

854

855

856

Figure 1. Previous recent hypotheses of early pterosaur relationships. $A$, the results of the 857 reduced taxon analysis by Britt et al. (2018); B, the results of the analysis by Dalla Vecchia (2019); C, the results of the analysis by Andres, Clark and Xu (2014).

858

Figure 2. Strict consensus rule tree produced in the initial analysis that did not utilise any new

859 anatomical characters. Nodes: 1, Preondactylia; 2, Caviramidae (clade novo); 3, Zambellisauria 860 (clade novo). 
862 Figure 3. Strict consensus rule tree produced in full analysis one, using equal weights

863 parsimony. Nodes: 1, Dinosauromorpha; 2, Dinosauriformes; 3, Dinosauria; 4, Pterosauria; 5,

864 Preondactylia; 6, Austriadraconidae; 7, Caviramidae (clade novo); 8, Zambellisauria (clade

865 novo); 9, Macronychoptera; 10, Dimorphodontidae; 11, Lonchognatha; 12, Novialoidea; 13,

866 Anurognathidae; 14, Caelidracones; 15, Monofenestrata; 16, Pterodactyloidea.

867

Figure 4. Strict consensus (A) and reduced strict consensus (B) trees produced when following

869 the analysis protocol of Ezcurra (2014) and using equal weights parsimony. White circle and

870 arrow indicate the position of Zambellisauria in this analysis.

871

872 Figure 5. Trees produced using implied weights implementation of parsimony for $k$ values $<10$

873 (A) and $k$ values $=10$ more (B). Coloured nodes and tips added to highlight the taxa whose 874 positions changed substantially between the implied weights parsimony analyses. White circles 875 and arrows indicate the position of Zambellisauria in each analysis.

Tables

879

Table 1. Sources of anatomical information for taxa added to the phylogenetic analyses. 
Figure 1

Previous recent hypotheses of early pterosaur relationships.

A, the results of the reduced taxon analysis by Britt et al. (2018); B, the results of the analysis by Dalla Vecchia (2019); C, the results of the analysis by Andres, Clark and Xu (2014).

A
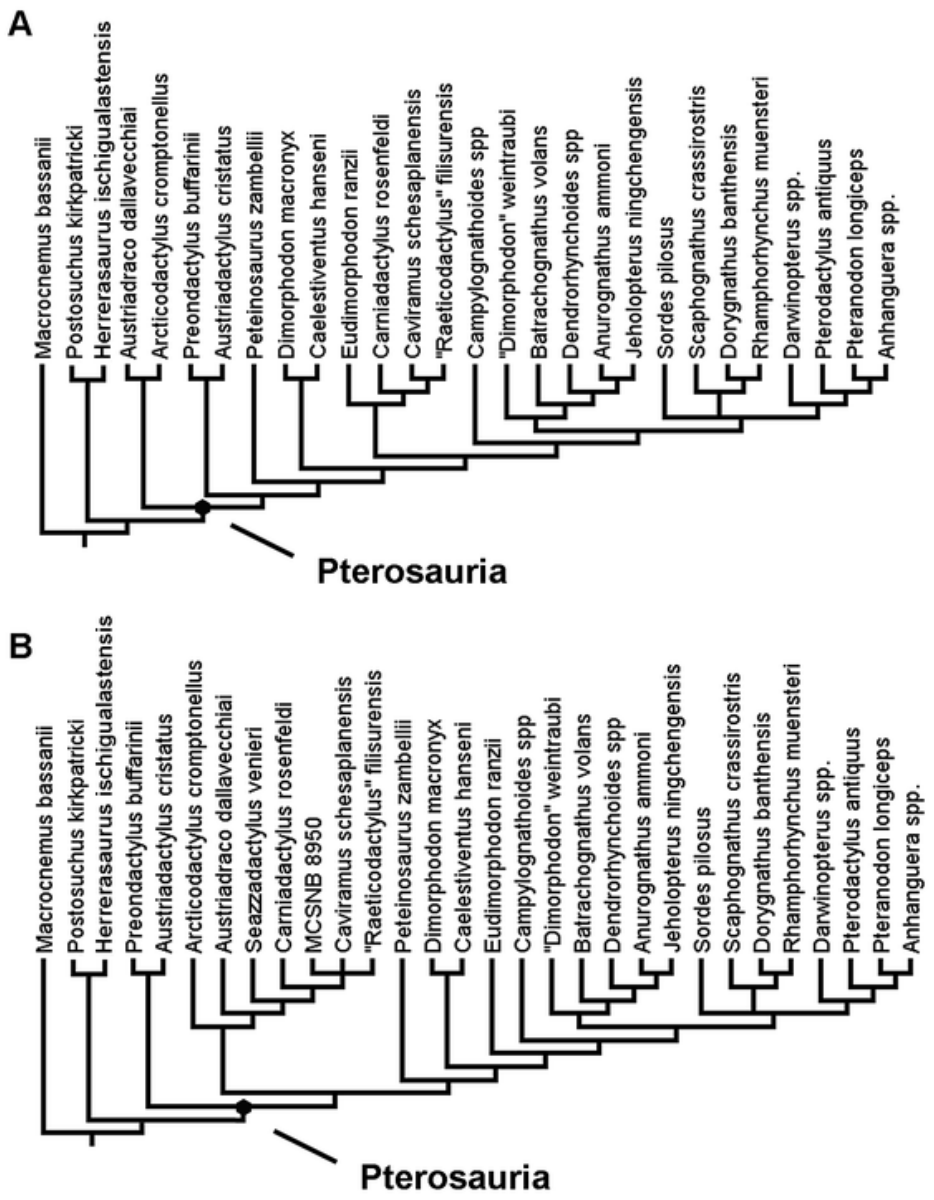

C

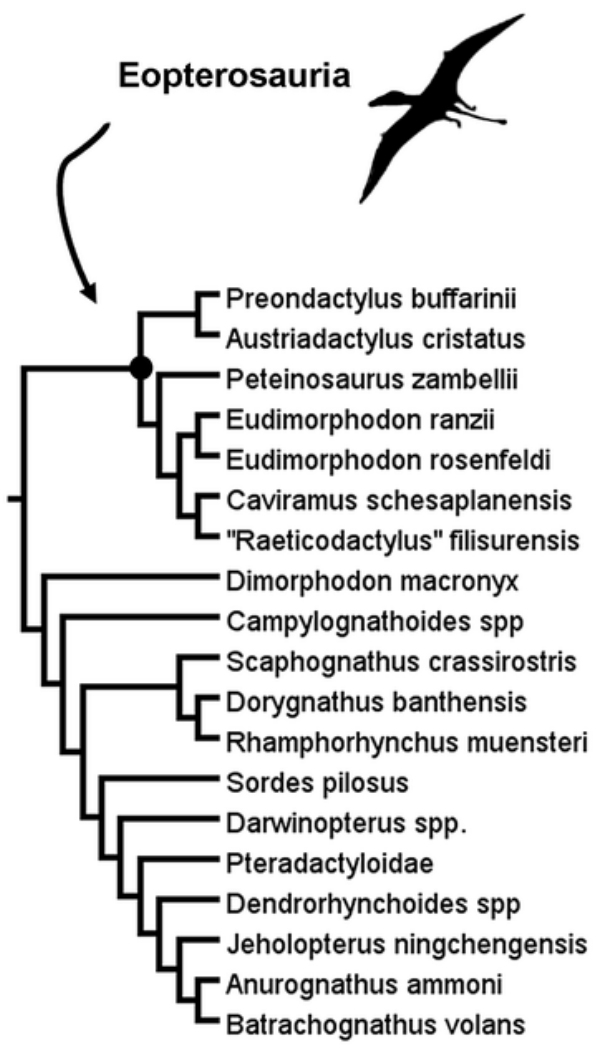


Figure 2

Strict consensus rule tree produced in the initial analysis that did not utilise any new anatomical characters.

Nodes: 1, Preondactylia; 2, Caviramidae (clade novo); 3, Zambellisauria (clade novo).

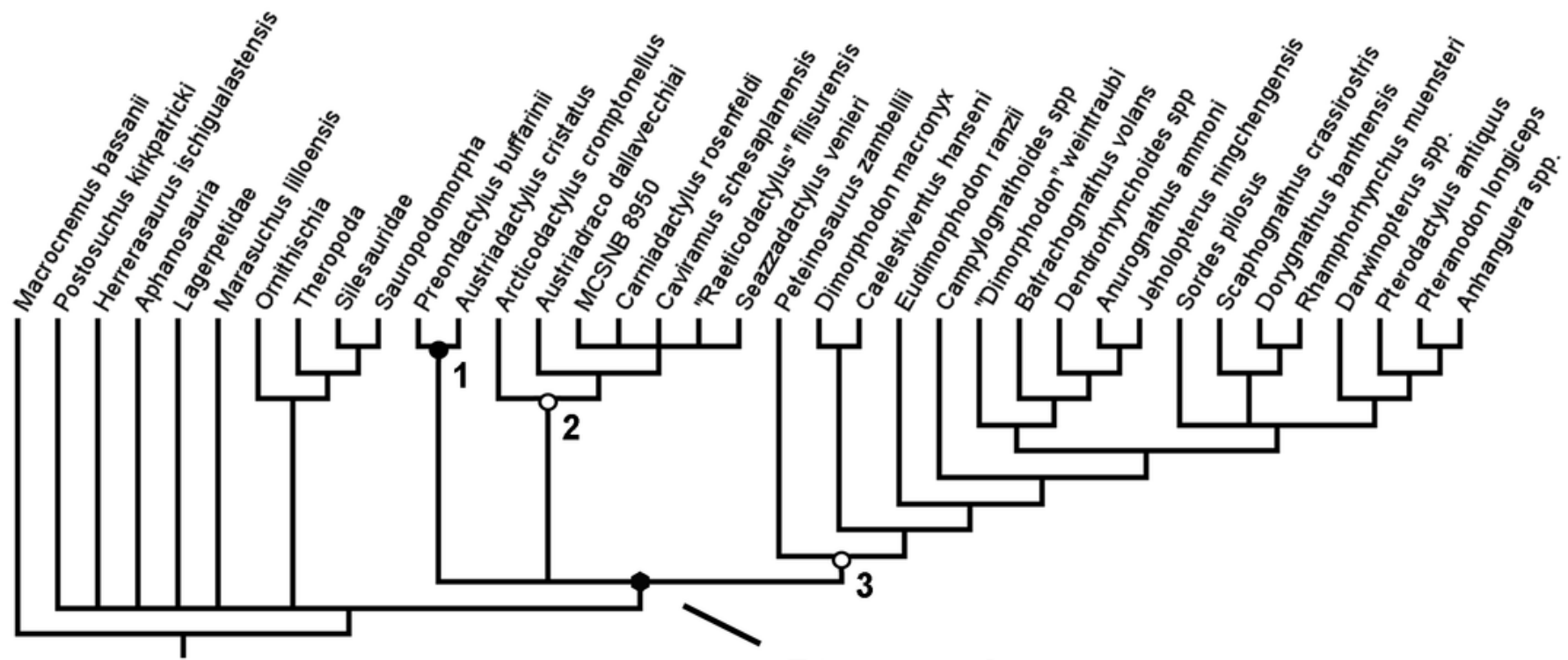

Pterosauria 
Figure 3

Strict consensus rule tree produced in full analysis one, using equal weights parsimony.

Nodes: 1, Dinosauromorpha; 2, Dinosauriformes; 3, Dinosauria; 4, Pterosauria; 5,

Preondactylia; 6, Austriadraconidae; 7, Caviramidae (clade novo); 8, Zambellisauria (clade novo); 9, Macronychoptera; 10, Dimorphodontidae; 11, Lonchognatha; 12, Novialoidea; 13, Anurognathidae; 14, Caelidracones; 15, Monofenestrata ; 16, Pterodactyloidea.

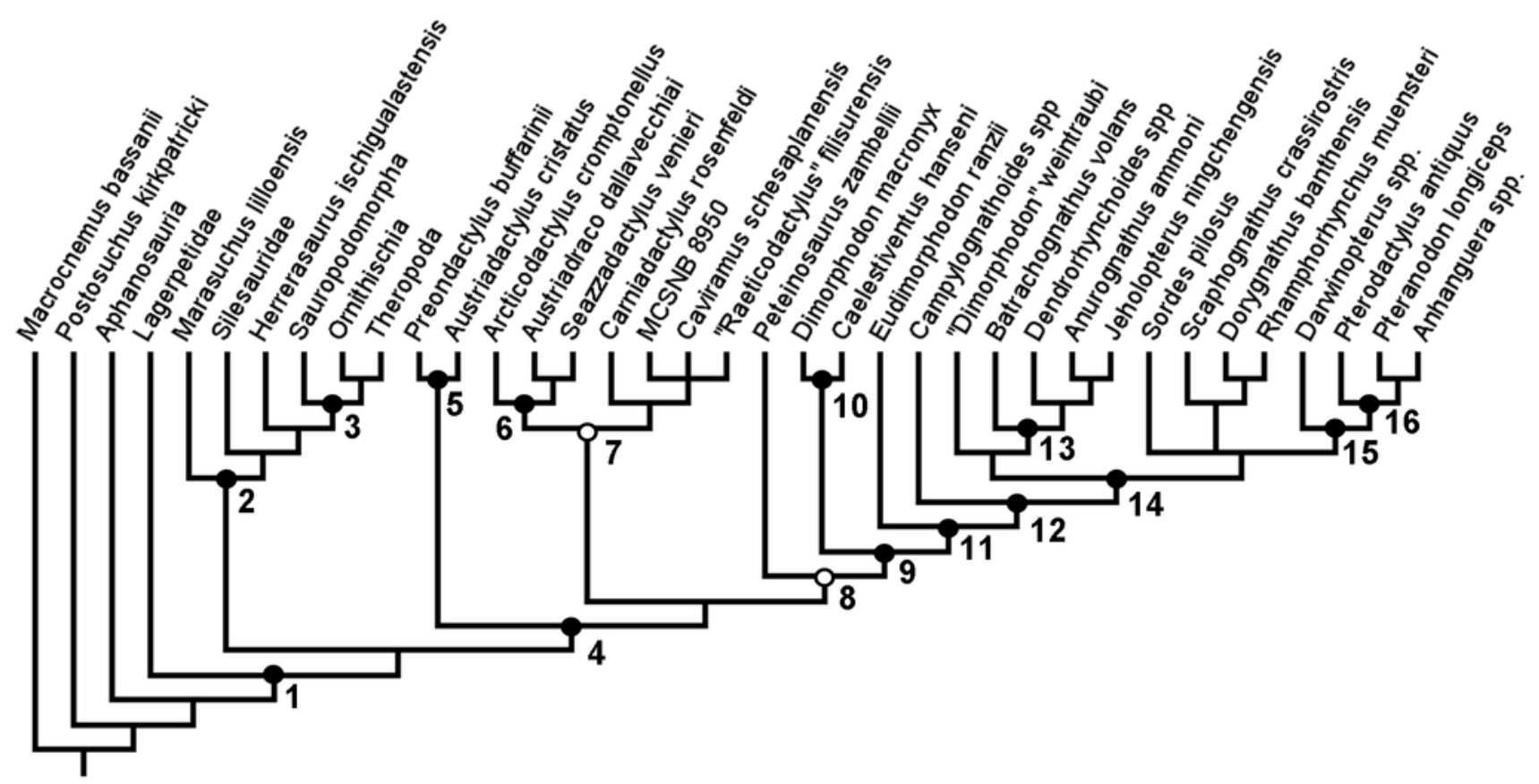


Figure 4

Strict consensus (A) and reduced strict consensus (B) trees produced when following the analysis protocol of Ezcurra (2014) and using equal weights parsimony.

White circle and arrow indicate the position of Zambellisauria in this analysis.
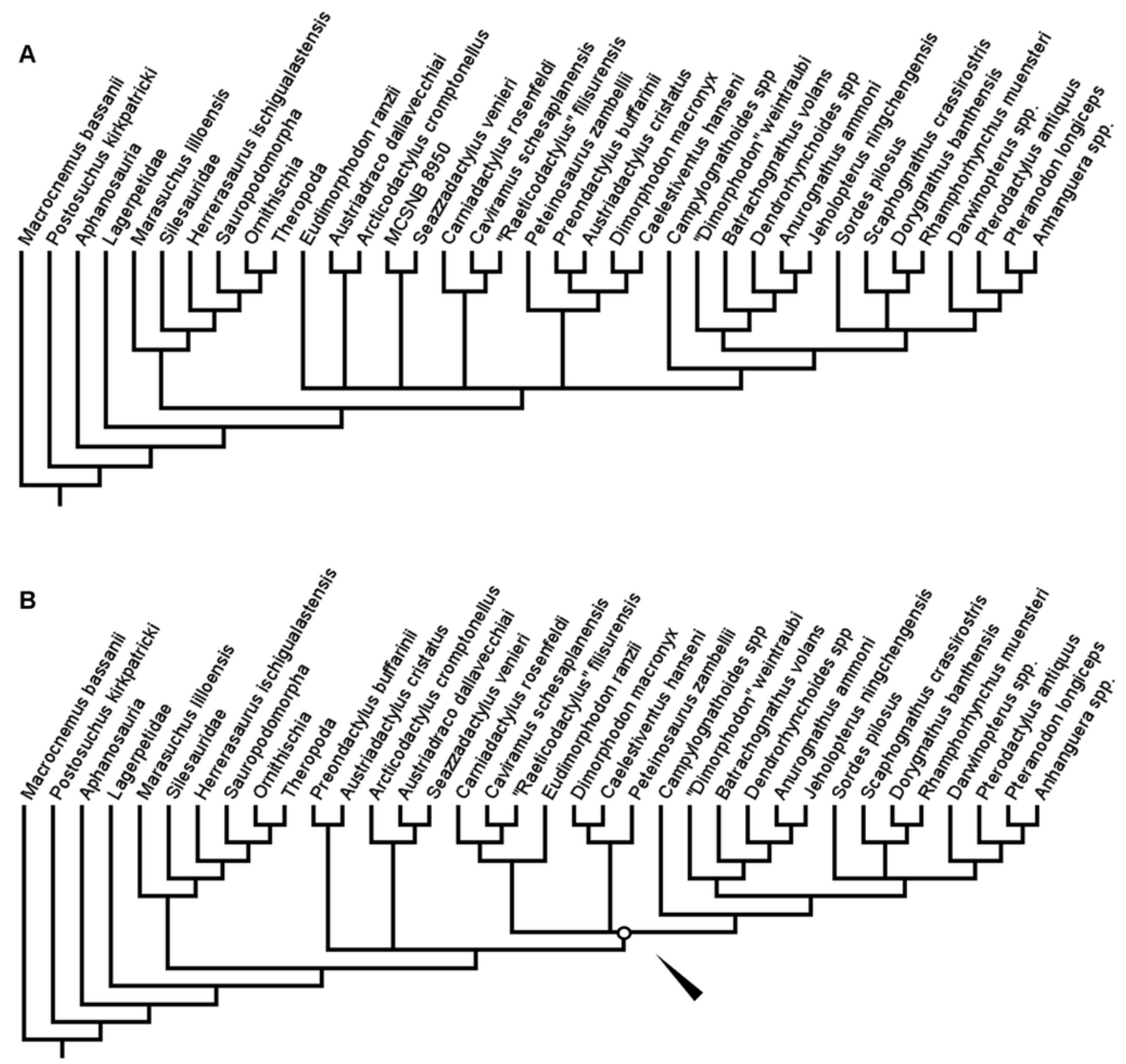
Figure 5

Trees produced using implied weights implementation of parsimony for $k$ values $<10$ (A) and $k$ values $=10$ more $(B)$.

Coloured nodes and tips added to highlight the taxa whose positions changed substantially between the implied weights parsimony analyses. White circles and arrows indicate the position of Zambellisauria in each analysis. 
A

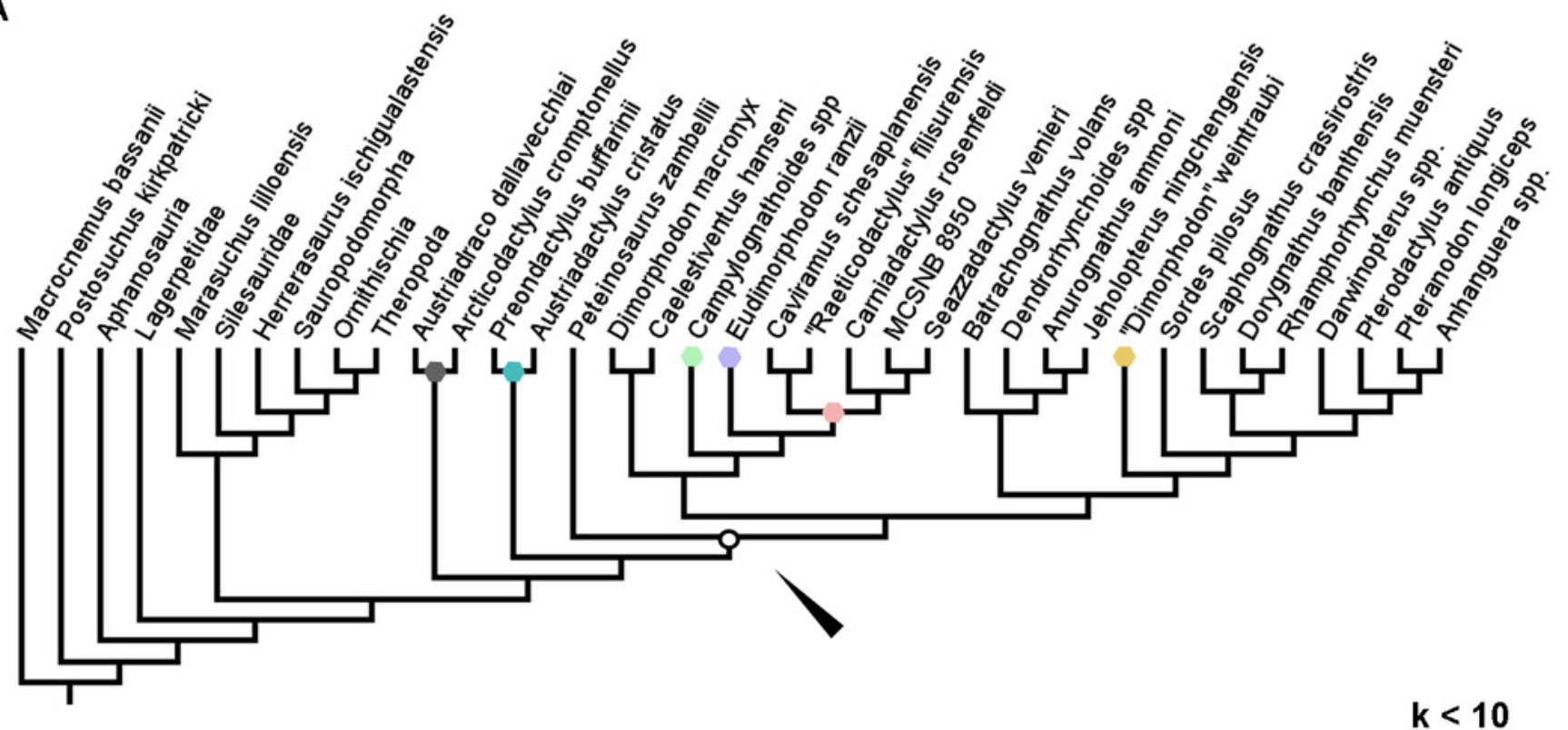

B

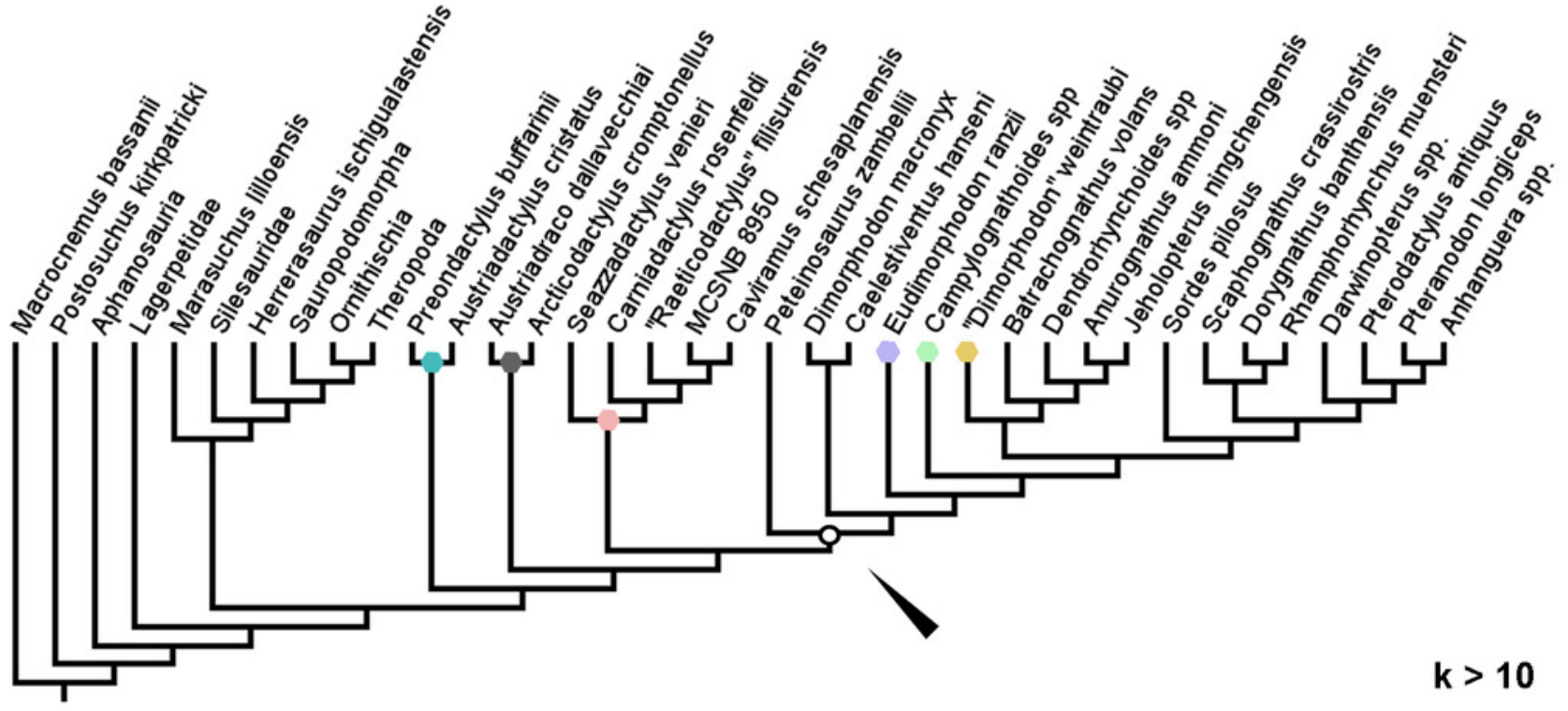




\section{Table 1 (on next page)}

Sources of anatomical information for taxa added to the phylogenetic analyses 


\begin{tabular}{|c|c|c|c|}
\hline Operational taxonomic unit & Based upon & Specimens & Sources \\
\hline \multirow[t]{3}{*}{ Aphanosauria } & Teleocrator rhadinus & NHMUK PV R6795-6 & Nesbitt et al. 2017, 2018 \\
\hline & Dongusuchus efremovi & Multiple - PIN & Nesbitt et al. 2017 \\
\hline & Yarasuchus deccanensis & Multiple - ISIR & Nesbitt et al. 2017 \\
\hline \multirow[t]{5}{*}{ Lagerpetidae } & Lagerpeton chanarensis & Multiple - PVL & specimens only \\
\hline & D. gregorii & TMM 31100-1306 & Nesbitt et al. 2009a \\
\hline & D. romeri & GR 218; DMNH EPV.29956 & Irmis et al. 2007; Martz \& Small 2019 \\
\hline & D. gigas & PVSJ 898 & Martínez et al., 2016 \\
\hline & Ixalerpeton polesinensis & ULBRA-PVT059 & Cabreira et al. 2016 \\
\hline Marasuchus lilloensis & Marasuchus lilloensis & Multiple - PVL & specimens only \\
\hline \multirow[t]{3}{*}{ Silesauridae } & Silesaurus opolensis & Multiple - ZPAL & Dzik 2003 \\
\hline & Kwanasaurus williamparkeri & Multiple - DMNH & Martz \& Small 2019 \\
\hline & Asilisaurus kongwe & $\begin{array}{l}\text { NHMUK R16303 } \\
\text { Multiple - NHMUK; SAM; }\end{array}$ & Nesbitt et al. 2010 \\
\hline \multirow[t]{3}{*}{ Ornithischia } & Hetero & BP & Butler et al. 2008; Norman et al. 2011; Galton 2014 \\
\hline & Lesothosauru diagnosticus & Multiple - NHMUK; BP & Knoll 2002a, b, c; Porro et al. 2015; Barrett et al. 2016; Baron et al. 2017c \\
\hline & Eocursor parvus & SAM-PK-K8025 & Butler 2010 \\
\hline \multirow[t]{3}{*}{ Theropoda } & Tawa hallae & Mutiple - GR & Nesbitt et al. 2009b \\
\hline & Coelophysis bauri & AMNH FR 7224 & specimens only \\
\hline & Eodromaeus murphi & Multiple - PVSJ & Martinez et al. 2011 \\
\hline \multirow[t]{5}{*}{ Sauropodomorpha } & Buriolestes schultzi & CAPPA/UFSM 0035 & Cabreira et al. 2016 \\
\hline & Pampadromaeus barberenai & ULBRA-PVT016 & Cabreira et al. 2011 \\
\hline & Saturnalia tupiniquim & Multiple - MCP & Langer et al. 1999; Langer 2003 \\
\hline & Eoraptor lunensis & PVSJ 512 & Sereno et al. 2011 \\
\hline & Plateosaurus engelhardti & Multiple - AMNH; SMNS & Nesbitt 2011 \\
\hline
\end{tabular}

